\title{
Bioinsumos
}

\section{Aplicación de bioinsumos en el cultivo de pimiento (Capsicum annuum) y su influencia en} parámetros biológicos del suelo

Adis*, María J; García, Roxana E; Romero, Amalia M; Cossoli, Marcela R; Iglesias Maria C ${ }^{(1)}$

(1) Cátedra de Microbiología Agrícola, Facultad de Ciencias Agrarias, UNNE, Corrientes, Argentina.

*E-mail: mariajoseadis@gmail.com

Introducción: El cultivo de pimiento bajo invernadero ocupa una importante superficie en la provincia de Corrientes. Dentro de las alternativas de manejo que complementan al sistema de producción podemos nombrar la inoculación con microorganismospromotores del crecimiento vegetal, la utilización de materiales ricos en nutrientes como el compost y lombricompost. Ambas herramientas además de contribuir al mejoramiento de los rendimientos, pueden tener relevancia en el aumento del tamaño y la actividad de las poblaciones microbianas. Estas características posicionan a la inoculación y al uso de lombricompost, como herramientas útiles que pueden complementar al sistema productivo. El objetivo del ensayo fue evaluar el efecto de bioinsumos tales como un inoculante ylombricompost en el cultivo de pimiento (Capsicum annuиm) y su influencia sobre la micorrización espontánea y la actividad respiratoria.

Materiales y métodos: El ensayo se estableció con plantines de pimiento híbrido Linus de 45 días, transplantados en macetas conteniendo un suelo arenoso $\left(\mathrm{pH} 6, \mathrm{CE} 0,14 \mathrm{dS} \cdot \mathrm{m}^{-1}, \mathrm{P} 24,8 \mathrm{mg} \cdot \mathrm{Kg}^{-1}, \mathrm{Ca} 4\right.$ cmol. $\mathrm{Kg}^{-1}, \mathrm{Mg} \mathrm{0,9}$ cmol. $\mathrm{Kg}^{-1}$, C.org. 0,468\%, $\mathrm{N}$ Total 0,028\%). Se efectuó un diseño completamente al azar de 4 tratamientos con 6 repeticiones: Testigo (T), Lombricompost (TL-dosis de 40 tn.ha ${ }^{-1}$ ), Inoculante Bradyrhizobium japonicum cepa E109 (TI- 1x10 $0^{9}$ UFC) y Fertilizante mineral (TF-12-11-18+ $\mathrm{Mg}, \mathrm{S}$ y microelementos-dosis equivalente a $\left.120 \mathrm{~kg} \cdot \mathrm{ha}^{-1}\right)$. La extracción de las plantas se efectuó en dos momentos, a los 30 y 60 días, tomando 3 repeticiones por muestreo. A los 30 días las variables evaluadas fueron altura $(\mathrm{H})$, número de hojas $(\mathrm{NH})$, número de pimpollos $(\mathrm{NP})$ y de flores $(\mathrm{NF})$. A los 60 días se continuaron con las variables reproductivas número de pimpollos (NP) y de flores (NF). Se determinó además en cada muestreo, peso seco vástago (PSV), peso seco radical (PSR), volumen radical (VR), biomasa total (BT) y relación vástago/raíz (PSV/PSR). Para la influencia sobre parámetros biológicos del suelo, se realizó tinción de raíces para observación de micorrizasy, a partir de suelo de la rizósfera de pimiento se determinó actividad respiratoria. Los datos fueron analizados mediante ANAVA y comparación de medias por prueba de Tukey $(\mathrm{p}<0,05)$.

Resultados: Los resultados obtenidos para el primer muestreo mostraron diferencias estadísticas significativas para la variable PSV, siendo mayor en Lombricompost respecto a los demás tratamientos. En la variable PSR se obtuvieron mayores valores en el tratamiento Lombricompost respecto al Inoculante, no siendo significativas estas diferencias respecto al Fertilizante y Testigo. En BT el valor más alto lo obtuvo el tratamiento Lombricompost diferenciándose estadísticamente del Testigo y el Inoculante, no así del Fertilizante. La relación PSV/PSR no mostró diferencias significativas entre tratamientos. En el segundo muestreo se mantuvo la misma tendencia que en el primer muestreo para la variable PSV y BT, siendo el tratamiento Lombricompost significativamente mayor a los tratamientos Inoculante y Testigo, no mostrando diferencias respecto al Fertilizante;para las variables PSR y relación PSV/PSRno se encontraron diferencias entre tratamientos. En ambos muestreos, las variables vegetativas $(\mathrm{H}, \mathrm{NH}, \mathrm{VR})$ y reproductivas (NP, NF) no mostraron diferencias estadísticas significativas, al igual que las variables relacionadas a la actividad microbiana del suelo, porcentaje de micorrización y actividad respiratoria.

Conclusiones: La inoculación con Bradyrhizobium no tuvo efecto como promotor del crecimiento en las plantas de pimiento. El lombricompuesto tuvo un efecto positivo sobre la producción de biomasa del cultivo, manteniéndose esta relación durante los dos períodos muestreados. Ninguno de estos bioinsumos aplicados tuvo efecto sobre la micorrización espontánea y la actividad biológica global. El trabajo mostró como mejor alternativa en este ensayo, la utilización de lombricompost para las etapas iniciales del cultivo. 